\title{
CONSIDERAÇÕES SOBRE A POSSIBILIDADE DA ADESÃO DA COMUNIDADE À CONVENÇÃO EUROPEIA DOS DIREITOS DO HOMEM ${ }^{1}$
}

\author{
Luís Pedro Cunha
}

\section{INTRODUÇÃO}

À primeira vista pode parecer pouco compreensível que duas ordens jurídicas, resultantes da convenção Europeia dos direitos do homem (CEDH) e da Comunidade Europeia do Carvão e do Aço (CECA), que foram criadas quase simultaneamente e no mesmo contexto regional, a Europa, tenham prescindido, quando da sua implementação, da previsão de um qualquer mecanismo de coordenação entre ambas. É fácil de ver, no entanto, que a criação de um mercado comum do carvão e do aço parecia não interferir, em razão da matéria, com direitos fundamentais. Por outro lado, os Estados vinculados por cada um dos tratados não coincidiam totalmente.

Com a criação da Comunidade Económica Europeia (CEE) e da Comunidade Europeia da Energia Atómica (CEEA), em 1957, a situação altera-se, não podendo considerar-se mais que, por força de limitações funcionais, as Comunidades não se veriam imbricadas em questões de direitos fundamentais.

Assim, sobretudo a criação da CEE, com importantes consequências ao nível das pessoas, bens e serviços, conduz inevitavelmente a frequentes situações de possível conflito entre o exercício do poder comunitário e a salvaguarda dos direitos individuais; veja-se, por exemplo, que o direito de propriedade ou a liberdade económica ou de escolha de profissão são afectados, ou podem sê-lo, por interdições de importação ou exportação de mercadorias, regulamentações de preços, organização de mercados agrícolas ou ainda pela aplicação das regras da concorrência.

Sintomática desta conflitualidade potencial é a existência de áreas de sobreposição entre disposições do Tratado de Roma (TCEE) e da CEDH, nomeadamente entre as disposições constantes do título III desse Tratado e aquelas constantes do $4^{\circ}$ protocolo adicional à Convenção (veja-se a liberdade de movimentos ou o respeito pela família e pala privacidade). 
Por outro lado, embora os Estados-membros da Comunidade tenham passado, ao longo destes trinta anos, de seis para doze, todos eles são actualmente signatários da Convenção.

Por tudo isto pode-se estranhar que não existam nenhuns laços formais entre a Comunidade e a CEDH, até porque o tratado constitutivo da CEE, em particular, não inclui nenhum catálogo de direitos fundamentais. Certos artigos, excepcionalmente, não deixam de oferecer alguma protecção nesse sentido, como sejam, por exemplo, a interdição de discriminações em razão da nacionalidade (art. $7^{\circ}$ TCEE) ${ }^{2}$, a existência de regras sobre a livre circulação (arts. $48 .^{\circ} \mathrm{ss}$. TCEE), o direito de estabelecimento (arts. $52 .^{\circ}$ ss TCEE), o princípio da igualdade de remuneração entre trabalhadores masculinos e trabalhadores femininos (art. 119. TCEE). De qualquer modo, e é de salientar desde já, esta protecção, para além de limitada funcionalmente, tem uma dimensão marcadamente finalística, adstrita à prossecução do objectivo da criação de um mercado único de factores de produção e de mercadorias.

Sendo assim, pode dizer-se que, pelo menos aparentemente, existe na Comunidade a situação paradoxal de não se lhe aplicarem as disposições da $\mathrm{CEDH}$ que obrigam todos os seus Estados-membros. Desta realidade surgem fortes críticas acompanhadas de sugestões várias, que analisaremos infra. Desta realidade surgiu também, por aquilo a que poderíamos considerar um "estado de necessidade", uma jurisprudência comunitária algo «sui generis», casuística, por um lado, mas pouco sujeita aos seus próprios precedentes, por outro. Do apelo dessa jurisprudência à Convenção surgiram, por fim, zonas de penumbra e riscos de conflitos (F. TOMAS): pergunta-se qual o fundamento jurídico para a aplicação da CEDH no quadro comunitário e assiste-se, no Conselho da Europa, a algum mal-estar decorrente do alrgamento implícito de competências que o Tribunal de Justiça das Comunidades Europeias (TJCE) tem levado a cabo; é bom ter presente que, por detrás de posições aparentemente altruístas, oculta-se um problema de competências. Esse problema tenderá, aliás, a agravar-se à medida que, por seu turno, os próprios orgãos da Convenção forem procedendo à elaboração de novos protocolos, de índole menos civil e política e mais económica e social.

\section{O MODO DE PROTECÇÃO DOS DIREITOS FUNDAMENTAIS NO CON- TEXTO COMUNITÁRIO; A EVOLUÇÃO JURISPRUDENCIAL.}

Numa primeira fase, o TJCE declarou-se incompetente para aferir da validade de actos comunitários que afectassem negativamente um direito reconhecido nalgum dos Estados-membros. Para alguns autores, esta atitude não só não foi um "pecado de juventude" do Tribunal como constituiu a sua tomada de posição mais sensata, visto que, na verdade, nem a questão da competência é líquida, nem é 
claro qual será o direito aplicável no âmbito comunitário ${ }^{3}$. Por outro lado, é de salientar que se o TJCE aplicasse disposições nacionais relativas aos direitos fundamentais, disposições essas que diferem de Estado para Estado, para aferir da validade de actos comunitários, estaria, por via dessa aplicação, a ameaçar a uniformidade da aplicação do direito comunitário, e, deste modo, a pôr fortemente em causa o seu efeito de integração (MARCOUX, 1983: 707).

Numa segunda e última fase, embora não isenta de nuances, o Tribunal considera-se competente e daí parte para a elaboração de uma jurisprudência qualificada por uns de "protectora" e, por outros, mais atentos ao seu carácter bastante progressivo, de "dinâmica".

Até 1975, data do Acordão Rutili, a Convenção não é objecto de referência expressa. Algo prudentemente, vai-se elaborando jurisprudência "à sombra da Convenção Europeia dos Direitos do Homem"" . Num Acordão de 1969 (Acordão Stauder) é feita a primeira referência à proteç̧ão dos direitos fundamentais; o TJCE inclui os direitos fundamentais nos princípios gerais de direito comunitário e considera-se competente para, pela via da observância desses princípios, assegurar o respeito por esses direitos fundamentais.

Logo no ano seguinte, em 1970 (Acordão Internationale Handelgesellschaft), o TJCE afirma que:

$1 .^{\circ}$ - the compete assegurar o respeito pelos direitos fundamentais garantidos pelos princípios gerais de direito.

Desaparecida portanto a necessidade de os princípios gerais de direito serem "comunitários", alarga-se o âmbito da fonte do direito e, nessa medida, alarga-se o quadro dos direitos fundamentais abrangidos. Pס̃e-se aqui o problema de se saber qual o fundamento para esta competência. MARCOUX ${ }^{5}$, entre outros, considera que a jurisprudência do Tribunal assenta numa interpretação extensiva dos arts. $164 .^{\circ}, 173 .^{\circ} \mathrm{e} 215 .^{\circ}$ do TCEE (mas também dos arts. $136 .^{\circ}$ do Tratado CEEA e $31 .^{\circ}$ do Tratado CECA). Nomeadamente no art. $164 .^{\circ}$ é referido que o Tribunal "garante o respeito do direito na interpretação e aplicação do presente tratado";

$2 .^{\circ}$ - em segundo lugar, o TJCE considera que, para a salvaguarda desses direitos, se inspirará nas tradições constitucionais comuns aos vários Estados-membros.

Com esta formulação, o Tribunal preservou o carácter autónomo da fonte de direito (os princípios gerais de direito), visto que não se vincula às tradições constitucionais dos Estados-membros, mas, por outro lado, conferiu a essas tradições a qualidade de fontes cognoscendi, o que, sem dúvida, renovou a dimensão reconhecida aos direitos fundamentais no quadro comunitário.

Por fim, esta passagem do Acordão revela-se também importante e deu azo a alguma polémica pela referência que fez de que as tradições constitucionais que importam são aquelas comuns aos Estados-membros; a partir daqui debateu-se, 
algo inconclusivamente, qual seria o nível de protecção dos direitos fundamentais que o Tribunal pretenderia, e deveria, assegurar;

3. - finalmente, o Tribunal afirmou que essa garantia do respeito pelos direitos fundamentais se deveria processar no quadro da estrutura e dos objectivos da Comunidade.

É tendo em conta essa estrutura e esses objectivos que não se pode estranhar que a jurisprudência comunitária tenha sobretudo incidido na garantia dos direitos fundamentais de índole económica e social, como sejam a liberdade económica e de profissão e o direito de propriedade ${ }^{6}$. Mas, se não é preocupante a limitação da garantia dos direitos fundamentais tendo em conta a estrutura da Comunidade, isto se entendermos que se pretende dizer que essa garantia está (funcionalmente) limitada pelo âmbito material das competências que lhe foram atribuídas, já é preocupante a limitação da garantia dos direitos fundamentais tendo em conta os objectivos da Comunidade, pois dessa limitação (finalística) podem decorrer riscos graves. Riscos esses que não serão aqueles mais comummente referidos, isto é, que não terão que ser a consequência de uma qualquer "superprotecção" dos direitos fundamentais.

Em 1974, por ocasião da resolução do caso Nold, o TJCE confere, pela primeira vez, um valor indicativo, referencial, aos "instrumentos internacionais que dizem respeito à protecção dos direitos do homem e aos quais os Estados-membros (...) aderiram (...)". Tal como em relação às tradições constitucionais comuns aos Estados-membros, o Tribunal considera esses instrumentos internacionais como fontes cognoscendi do direito e, mais uma vez, não menciona expressamente a CEDH; a razão de todas estas formulações vagas deve-se ao facto de que a França ainda não tinha ratificado a Convenção.

Logo após essa ratificação, a Convenção passa a ser referida expressamente: o caso Rutili (1975), a directiva 64/221 é interpretada de harmonia com os arts. $8 .^{\circ}$ e $11 .^{\circ} \mathrm{da}$ CEDH e com o art. $2 .^{\circ}$ do $4 .^{\circ}$ protocolo. ${ }^{7} \mathrm{O}$ Tribunal, no entanto, e no âmbito da sua jurisdição, insiste na "aplicação" da Convenção pela via da observância dos princípios gerais de direito e, por acréscimo, parece continuar apenas a reconhecer à Convenção em particular, e aos instrumentos internacionais em geral, um valor meramente indicativo.

Em 1977, os orgãos não jurisdicionais da Comunidade, vencidas algumas reticências da Comissão, produzem uma Declaração Comum onde, afirmando que consideravam a CEDH como valor de referência no respeito pelos direitos fundamentais, a prosseguir pela Comunidade no exercício dos seus poderes e na prossecução dos seus objectivos, não mais fazem do que comungar da posição do Tribunal. Esta Declaração, pelo seu carácter político e de co-responsabilização pelo pragmatismo jurisprudencial, consolidava definitivamente o princípio da protecção dos direitos fundamentais no âmbito comunitário, facto de que o próprio TJCE deu nota em 1979 (caso Hauer). 
A partir deste momento, o Tribunal sente-se à vontade para aplicar a Convenção ${ }^{8}$ : em Março e Maio de 1980 (casos Pécastaing e Panasonic) direito comunitário derivado é julgado em conformidade com preceitos da Convenção ${ }^{9}$; no segundo destes casos, foi mesmo dispensada, pela primeira vez, a menção de que a aplicação da CEDH se fazia pela observância dos princípios gerais de direito, parecendo poder-se concluir que, para o Tribunal, as disposições dessa Convenção, aplicáveis no âmbito do direito comunitário, faziam, desde logo, parte integrante da ordem jurídica comunitária.

Em consonância com este espírito, o TJCE, em 1986 (Acordão Margurite Jonhston c/ Royal Ulter Constabulary), considerou que a emissão de um certificado ministerial, não passível de recurso, justificando uma situação de discriminação ao acesso a empregos públicos por necessidades de segurança pública, violava $\left(1 .^{\circ}\right)$ uma directiva comunitária, relativa à abolição da discriminação entre homens e mulheres, $\left(2 .^{\circ}\right)$ as tradições constitucionais comuns aos estados-membros e $\left(3 .^{\circ}\right)$ os artigos $6 .^{\circ}$ e $13 .^{\circ}$ da $\mathrm{CEDH}$ (garantia de via jurisdicional). Deste modo, uma obrigação contida na $\mathrm{CEDH}$ impôs-se na ordem jurídica interna britânica, através da jurisprudência comunitária. Todavia, deve ser realçado que, num caso com alguma similitude, datado do ano anterior (caso Cinéthèque), em que se argumentava com a imcompatibilidade entre a $\mathrm{CEDH}$ e (apenas) a lei francesa, o TJCE se considerou incompetente; é de concluir então, salvo melhor opinião, que a jurisprudência comunitária é suficientemente pragmática para interpretar direito comunitário de harmonia com disposições da Convenção (valor indicativo), pode mesmo julgar da conformidade de direito comunitário derivado com disposições da Convenção (valor vinculativo) e, mais recentemente, considera-se ainda competente para julgar da conformidade de actos administrativos internos dos Estados-membros com disposições da Convenção, desde que esses actos também sejam julgados (e considerados) ilícitos face ao próprio direito da Comunidade.

\section{ANÁLISE DA JURISPRUDÊNCIA}

A jurisprudência comunitária, neste campo, como em outros, faz-se realçar pelo seu carácter pragmático, ou espontâneo, como dizem alguns autores, ou informal, como dizem outros; convém salientar que a esse pragmatismo, ou a essa "espontaneidade", não obstou uma grande cautela. Como se viu, a técnica de introduzir a protecção dos direitos fundamentais na ordem jurídico-comunitária consistiu na subsunção desses direitos nos princípios gerais do direito, em relação aos quais o tribunal se considera inequivocamente sujeito, mas cuja autonomia, como fonte, não é discutível. Sendo assim, o TJCE, arrogando-se competências implícitas, vai "exumando", em cada caso concreto, um direito mais ou menos 
implícito. Assim se evita integrar abertamente na ordem jurídica comunitária as disposições da Convenção.

Em relação à especificidade das funções desses princípios gerais de direito (e das disposições da Convenção), os autores costumam salientar uma ou outra; em termos gerais, essas funções podem ser sistematizadas em três. Assim, o Tribunal apela para os princípios, ou para as disposições da Convenção, como:

a) auxiliares de interpretação do direito comunitário originário e derivado;

b) modo de integração de lacunas do direito comunitário originário e derivado;

c) parâmetros de aferição da validade de actos adoptados pela Comunidade ou pelos próprios Estados-membros.

Da análise destas funções conclui-se que os princípios gerais de direito, em geral, e a Convenção, em particular, têm, no contexto comunitário, sinteticamente, uma dupla inserção: como instrumento de interpretação, "auxiliar" de legitimação, e como "elemento jurídico a ter em conta no sistema de direito comunitário" (como afirma PESCATORE ${ }^{10}$, defendendo que o direito aplicável no âmbito comunitário não é apenas aquele que foi escrito originariamente e depois, em cumprimento dos Tratados, mas inclui também outras regras jurídicas necessárias, mas não especificadas).

Uma possível virtude do carácter pragmático da jurisprudência do Tribunal foi a de conseguir proteger os direitos fundamentais sem que se tenha assistido, da sua parte, a um comprometimento explícito de observar um qualquer nivel ou standard de protecção ${ }^{11}$. Tal comprometimento conduziria, por certo, a situações de fricção com aquelas jurisdições constitucionais que considerassem que a jurisprudência do Tribunal estaria a "pecar", quer por "excesso", quer por "defeito"12; ora, sendo a garantia da unidade e da aplicação uniforme do direito comunitário essencial, é normal que, por um lado, o recurso às tradições constitucionais comuns aos Estados-membros, ou, se se quiser, o recurso aos princípios gerais de direito comuns aos Estados-membros, não obrigue o TJCE a limitar-se, no âmbito da aceitação desses princípios, ao mínimo denominador comum; por outro lado, também é normal que o TJCE não adopte , nesta matéria, um critério maximalista "absoluto" (segundo o qual será inválido todo o acto comunitário que contenda com um qualquer direito garantido por uma Constituição de um dos Estados-membros ${ }^{13}$. A solução encontrada será aquela que, sendo a melhor de acordo com os objectivos dos Tratados, ou até a mais progressiva tendo em conta aqueles objectivos (justificação autónoma), procure, simultaneamente, a obtenção de um grau razoável de convergência entre os níveis de protecção conferidos pelas várias ordens jurídicas nacionais (comparação qualitativa); procurar-se-á, em suma, seguir um "critério maximalista flexível" (MARCOUX, 1983: 722), esperando-se, deste modo, alcançar uma solução que não prejudique o efeito de integração da ordem jurídica comunitária. 
Nenhuma das soluções, no entanto, consegue eliminar o risco da rebelião das jurisdições constitucionais dos Estados-membros. De todas elas, a última é sem dúvida aquela que mais atenua esse risco, incorrendo-se, todavia, em custos ao nível da segurança e certeza jurídicas.

Várias críticas têm sido apontadas a toda esta construção. Em primeiro lugar, receia-se o gouvernement des juges e salienta-se que a natureza dos direitos fundamentais é pouco compatível com um droit prétorien ${ }^{14}$. No âmbito deste tipo de soluções jurisprudenciais, afirma-se, padece-se de insuficiência em direito aplicável e da insegurança decorrente do facto de se aplicarem apenas princípios gerais, por parte de um orgão judicial que nem sequer está vinculado aos seus próprios precedentes. Teme-se também uma aplicação forçada desses princípios, ou seja, teme-se uma superprotecção dos direitos fundamentais.

Por outro lado, discorre-se largamente acerca dos perigos de que se reveste uma protecção condicionada dos direitos fundamentais. Isto porque, para o TJCE, só é sua função proteger direitos substantivos quando a necessidade do respeito por esses direitos se encontrar em conexão com uma actividade económica abrangida pelos fins comunitários, isto é, quando essa protecção for necessária para a prossecução dos fins comunitários. É consensual concluir-se que deste condicionalismo resulta uma limitação à proteç̧ão dos direitos fundamentais. WEILER ${ }^{15}$ acentua mesmo esses perigos: na sua opinião, mais do que simples limitações, a proteç̧ão dos direitos fundamentais pode sofrer de verdadeiras lacunas; isto porque, sabido qual é o empenho do Tribunal na construção da Europa comunitária, pode perguntar-se qual será a atitude desse orgão se se confrontarem direitos fundamentais e, por exemplo, aspectos essenciais, que não meras questões técnicas, de importantes políticas comunitárias. Para este autor, este é o risco que se corre com maior probabilidade do que, por exemplo, aquele de se verificar uma "superproteç̧ão" dos direitos fundamentais. As consequências serão também, com toda a certeza, bastante mais gravosas.

Por fim, critica-se a solução jurisprudencial pelos riscos que envolve de dar origem a conflitos entre instituições comunitárias e os orgãos da Convenção, sabendo-se que o alcance da protecção dos direitos fundamentais, por parte do TJCE, não tem sido delimitado de forma precisa, nem a sua relação com a extensão das competências comunitárias foi perfeitamente fundamentada.

\section{A POSSIBILIDADE DE ADESÃO DA COMUNIDADE À CONVENÇÃO EUROPEIA DOS DIREITOS DO HOMEM.}

Existem várias possibilidades jurídico-políticas quanto ao modo futuro de se protegerem os direitos fundamentais da Comunidade; todas elas têm sido extensamente debatidas ${ }^{16}$, apontando-se essencialmente em três direcções: adesão à Convenção (que, contudo, não obste à reafirmação do carácter pragmático de 
jurisprudência posterior e que mais não seja do que o modo, transitório, de proteger os direitos fundamentais até à elaboração de um catálogo autónomo), elaboração desde já desse catálogo e aprofundamento de uma cooperação interinstitucional entre o TJCE e o Tribunal Europeu dos Direitos do Homem (TEDH) ${ }^{17}$.

Esta última possibilidade, referida por alguma doutrina ${ }^{18}$, e pela Comissão, em 1976, defende que, tendo em conta os níveis de proteç̧ão dos direitos fundamentais assegurados por ambas as ordens jurídicas, a penetração na jurisprudência comunitária de princípios que também estão na base da $\mathrm{CEDH}$, a ausência de conflitos entre a aplicação do direito comunitário e a aplicação do direito da Convenção, não é necessário nenhum procedimento especial neste domínio para além de um simples aprofundamento de uma cooperação interinstitucional (através de troca de pareceres e de opiniões sobre métodos de interpretação, princípios gerais de direito, noção de não-discriminação, etc.). Mais ainda, argumenta-se também que o facto de todos os Estados-membros da Comunidade já se encontrarem vinculados à CEDH inviabiliza a produção de actos comunitários desrespeitadores das obrigações assumidas previamente por esses Estados-membros. Com esta última argumentação encontramo-nos a um passo da argumentação baseada nos Acordãos GATT e, por conseguinte, bastante próximos da posição de PESCATORE, que referiremos infra.

No quadro da primeira solução (que poderíamos considerar mista), adoptada, por exemplo, pela Comissão no seu Memorandum de 1979, estima-se que a adesão à CEDH, para além de produzir desejáveis efeitos cosméticos, constituiria (mais) uma etapa na consolidação da protecção dos direitos fundamentais na Comunidade, que tanto mais é necessária quanto maior é o alargamento das competências comunitárias. A CEDH deixaria assim de ser simplesmente uma fonte cognoscendi do direito para se afirmar como fonte primária, resolvendo-se deste modo o problema da competência e do direito aplicável, com ganhos ao nível da segurança e certeza jurídicas ${ }^{19}$, e terminando, simultaneamente, o "vazio" de controlo sobre a jurisdição comunitária.

Todavia, tal adesão não dispensaria que, numa segunda etapa, as instituições democráticas elaborassem um catálogo autónomo de direitos fundamentais, nem obstaria a que o TJCE, mesmo após a adesão, reincidisse na sua elaboração de uma jurisprudência casuística, com o objectivo de melhor proteger os direitos fundamentais. Isto até porque a CEDH não incide particularmente em direitos económicos e sociais ${ }^{20}$.

Por conseguinte, nos termos de BROWN e McBRIDE ${ }^{21}$, a Comunidade deveria socorrer-se da Convenção ( $a$ ready-made list), enquanto se espera pela criação de um catálogo autónomo de direitos fundamentais (a tailor-made catalogue) ${ }^{22}$.

Este catálogo, e até a sua criação imediata, apresentaria a vantagem, em relação à adesão, de representar uma nova peça de aquilo que se poderia qualificar de legislação constitucional europeia, reforçando a legitimação jurídico-constitucio- 
nal da comunidade (e, porventura, induzindo nos mais incautos uma imagem de estado "federal" ...).

Não é, no entanto, difícil de prever fortes dificuldades na sua elaboração, sobretudo quando se abordasse o tratamento a dar aos direitos económicos e sociais, ultrapassados que fossem os direitos "clássicos" de defesa, onde existe um largo consenso. Para a resolução destas dificuldades ter-se-ia que subscrever claramente uma solução minimalista, maximalista, ou então intermédia, de protecção aos direitos fundamentais, que, vista a heterogeneidade dos figurinos jurídico-constitucionais dos Estados-membros, deixaria sempre alguns deles descontentes.

\section{A QUESTÃO DO FUNDAMENTO JURÍDICO DA ADESÃO}

Para a Comissão e para a generalidade dos autores que defendem a adesão, a invocação da CEDH por parte do TJCE corresponde à integração de facto dessa Convenção no direito comunitário. Tal significa que existe desde já uma situação de facto com repercussões jurídicas que convém formalizar, pelos motivos já aludidos.

PESCATORE ${ }^{23}$, todavia, exprime a conviç̧ão de que se está perante um "falso problema". Para este autor, a Convenção já vigora no ordem jurídica comunitária; como fundamento, PESCATORE invoca a doutrina da sucessão de Estados: os Estados-membros, nos tratados que instituíram, com rigor, três Comunidades (CECA, CEEA e, fundamentalmente, CEE), transferiram para as mesmas importantes poderes em matérias económicas e sociais. Por conseguinte, essas Comunidades sucederam aos Estados-membros na legislação e gestão dessas matérias; há uma sucessão funcional e limitada das Comunidades em relação aos Estados-membros ${ }^{24}$. Como tal, as Comunidades sucedem-lhes também, integralmente, nas obrigações impostas pela CEDH respeitantes a essas ex-parcelas das jurisdições nacionais. Neste ponto da sua argumentação o autor chama à colação a jurisprudência GATT, em que o TJCE considerou que, segundo o princípio da substituição, os acordos multilaterais (neste caso de índole comercial) celebrados pelos Estados-membros vinculam a CEE, quando lhe são transferidas as respectivas competências. Concluindo, o TJCE encontra-se, face à CEDH e aos seus órgãos, na mesma situação que os tribunais internos dos Estados-membros da CEDH; face à CEDH e aos seus órgãos, o TJCE é um órgão jurisdicional interno e o facto de o mesmo aplicar a CEDH resulta, não de uma qualquer "boa-vontade", mas sim do cumprimento de uma obrigação jurídica.

Em resumo, para PESCATORE o princípio de substituição fundamenta a sua posição de que a Comunidade sucedeu, embora funcional e limitadamente, nas obrigações contraídas pelos seus Estados-membros, face à CEDH. Não houve, nem podia haver, nhenhuma ruptura na situação jurídica ou no nível de protecção dos indivíduos assegurada pela Convenção. ${ }^{25}$ 
FERNANDEZ TOMAS ${ }^{26}$ critica esta utilização do princípio da substituição: segundo o autor, o âmbito deste princípio tem limitações, limitações essas que se prendem com a natureza das competências que os Estados-membros transferiram para a Comunidade; ora os Estados-membros não transferiram para a Comunidade competências que extravasam abertamente dos fins comunitários, como seja a aplicação da CEDH (isto é, a CEDH de forma alguma faz parte do direito comunitário). Mesmo no plano dos direitos substantivos enumerados pela $\mathrm{CEDH}$, a sua protecção, por parte do TJCE, só será possível quando a observância desses direitos estiver em conexão com uma actividade económica abrangida pelos fins comunitários (isto é, a protecção dos direitos fundamentais, nesse caso concreto, será necessária para a prossecução dos fins comunitários). Assim o limite ao princípio da substituição, mais do que meramente funcional, é também finalístico.

Também bastante criticada é a utilização da jurisprudência GATT: existem, segundo vários autores, diferenças substanciais entre a substituição dos Estados-membros pela CEE no âmbito dos Acordos GATT e uma possível substituição dos Estados-membros pela Comunidade no âmbito da proteç̧ão dos direitos fundamentais. Em primeiro lugar, e como já se disse, a competência para a definição e orientação da política comercial, no quadro da qual se incluem os referidos Acordos, foi expressamente transferida para a CEE (como aliás não poderia deixar de ser, tendo em conta que os Estados-membros se integraram numa união aduaneira); todavia, no âmbito da protecção dos direitos fundamenatis, tal transferência de competências não se verificou. Em segundo lugar, é de referir que a jurisprudência GATT considerou como um facto justificativo da sucessão o reconhecimento dessa sucessão, mesmo que tácito, por parte das outras partes contratantes. Este reconhecimento ainda não ocorreu, no que respeita à CEDH ${ }^{27}$. Por fim, chama-se a atenção para que, também contrariamente ao que se tinha passado no âmbito do GATT, alguns dos Estados-membros só aderiram à CEDH depois de aderirem à Comunidade, o que parece prejudicar a ideia de uma sucessão, mesmo que funcional.

Uma última dificuldade que é apontada para a aceitação da perspectiva de PESCATORE reside no facto de que, embora já todos os Estados-membros da Comunidade tenham aderido à Convenção, fizeram-no com diferentes reservas e não aderiram uniformemente aos vários protocolos; esta realidade torna inviável uma transferência ímplicita, e portanto necessariamente homogénea, de competências.

\section{CONSEQUÊNCIAS SUBSTANTIVAS E PROCESSUAIS DA ADESÃO}

Em termos substantivos, que consequências práticas decorrerão da adesão? DAUSES $^{28}$ considera que não existiriam nenhumas no que respeita ao nível da protecção do indivíduo. BROWN e McBRIDE ${ }^{29}$ interrogam-se se a adesão, e a 
superação de todas as dificuldades daí decorrentes, compensará em termos de melhoramento do nível de protecção dos direitos fundamentais ... do que não restam dúvidas é que a adesão pode produzir um efeito perverso se, em virtude das várias ratificações com reservas dos vários Estados-membros, a mesma se vier a processar pelo nível mais baixo de protecção. Naturalmente, essa solução resultará insatisfatória para alguns desses Estados, que não poderiam admitir que a uma transferência de poderes soberanos correspondesse uma diminuição do nível de protecção dos direitos fundamentais garantido pelas suas Constituições. Poder-se-ia tentar obviar a esta situação adoptando uma interpretação extensiva do nível maior de protecção comum, mas, também nesta hipótese, teríamos Estados que não aceitariam de bom grado a solução adoptada. Consequentemente, sempre se poderiam verificar resistências na execução dos Acórdãos comunitários, com implicações graves ao nível da aplicação uniforme do direito comunitário e do seu efeito de integração. Implicações estas que são sempre de salientar.

Ao nível processual, o TJCE e o TEDH, no caso da adesão, teriam obrigatoriamente que delimitar as suas competências e introduzir alterações nos respectivos processos jurisdicionais. ${ }^{30}$ Tais "arranjos" institucionais só não seriam necessários se se perspectivasse a adesão apenas em termos substanciais. Esta, aliás, é a posição de autores como LEUPRECHT ${ }^{31}$; pretender-se-ia assim resolver o problema do direito aplicável, excluindo da adesão, contudo, os mecanismos de garantia previstos na CEDH.

Com este propósito, sugeriram-se dois critérios "liminares" de repartição de competências entre o TJCE e o TEDH:

a) critério "material".

A questão da repartição de competências resolver-se-ia determinando que o TJCE é competente para sanar litígios decorrentes da pretensa violação de direitos substantivos constantes de um acto formalmente comunitário. Mas, se a menção desses direitos não for mais do que uma duplicação de direitos substantivos constantes na CEDH, então temos que essa duplicação pode dar origem a uma "duplicação" de competências em razão da matéria e, assim, a uma duplicação de processos;

b) critério formal.

Determinar-se-ia que o TJCE seria competente para controlar os actos das instituições comunitárias que violassem direitos fundamentais, mesmo que constantes da CEDH, e o TEDH seria competente para controlar os actos emanados pelos seus Estados-membros. No primeiro caso, o controlo judicial efectura-se-ia por via do art. 173. ${ }^{\circ}$ TCEE. No segundo caso, o controlo iniciar-se-ia pela Comissão Europeia dos Direitos do Homem.

Levanta-se, contudo, um obstáculo a esta solução: o TJCE também é competente para controlar actos emanados dos seus Estados-membros, pela via dos 
arts. $169 .^{\circ}$ e $170 .^{\circ}$ e, a título prejudicial, pela via do art. $177 .^{\circ}$. Assim, também segundo este critério, poderia haver uma duplicação de processos (se um acto de um Estado-membro violasse a CEDH e o acto comunitário seu duplicado). No segundo caso acima referido (art. $177 . .^{\circ}$ ), um particular poderia mesmo ver o seu caso ser analisado em primeiro lugar pelo TJCE.

Face à insufuciência destas pretensas soluções, que não só não resolvem o problema da repartição de competências como tendem a complicá-lo, é de considerar, em alternativa, uma solução que, prevendo a adesão da Comunidade à CEDH também em termos processuais ${ }^{32}$, harmonize as possibilidades de actuação dos orgãos de garantia previstos tanto pela CEDH como pelos tratados comunitários.

Essa "solução" terá que prosseguir dois objectivos: por um lado, manter a autonomia de cada ordem jurídica (e de cada Tribunal) no seu domínio próprio e, por outro, harmonizar os respectivos processos jurisdicionais. No plano institucional, tal significa proceder a uma divisão de competências (1) de última instância e (2) de interpretação "autêntica", para cada "grupo" de direitos fundamentais autónomos.

LECOURT ${ }^{33}$ considera estes dois objectivos como demasiado contraditórios para serem prosseguidos simultaneamente. Em nossa opinião, não serão contraditórios se se distinguirem áreas de harmonização de áreas de autonomia:

a) áreas de harmonização: será necessário harmonizar os vários processos jurisdicionais para assegurar uma interpretação "autêntica", seja dos Tratados comunitários, seja da CEDH, a levar a cabo, respectivamente, pelo TJCE e pelo TEDH, sempre que dessa interpretação depender uma decisão jurisdicional. Assim, uma decisão jurisdicional de um dos Tribunais pode sempre estar dependente da resolução de uma questão prévia, a colocar ao outro Tribunal. O mecanismo de reenvio seria similar àquele já previsto no art. $177 .^{\circ}$ do TCEE (reenvio prejudicial estabelecido entre as jurisdições nacionais e o TJCE, no âmbito do direito comunitário).

A grande dificuldade a apontar a esta solução de harmonização é a de implicar maior complexidade e mais delongas nos processos judiciais; por exemplo, um processo poderia "ocorrer" de um tribunal nacional de $1 .^{a}$ instância para a Relação, daí para o Supremo, de onde seria enviado, para resolução de questão prévia, para o TJCE que, por sua vez, poderia considerar o reenvio prejudicial ao TEDH. Deste Tribunal o processo retornaria ao TJCE que, finalmente, comunicaria a sua decisão ao Supremo. Processos como estes demorariam, sem dúvida, anos, e poderiam implicar tais atrasos nas tomadas de decisão do TJCE a título prejudicial, com base no art. $177 .^{\circ}$ do TCEE, que o interesse prático do referido artigo, fundamental como instrumento de integraação jurídica, resultaria fortemente diminuído;

b) áreas de autonomia: será necessário que a Comunidade reconheça a competência do TEDH, portanto a autonomia da sua jurisdição sobre os "seus" direi- 
tos fundamentais. Este reconhecimento compreenderia a aceitação, pela Comunidade, do direito de recurso para o TEDH por parte dos Estados-membros e, eventualmente, do direito de recurso por parte de indivíduos (isto é, este reconhecimento compreenderia a aceitação da qualidade do TEDH como tribunal de última instância). ${ }^{34}$

Como se sabe, nos termos da CEDH (art. 26..$^{\circ}$ ), é requisito de admissibilidade de uma queixa o esgotamento dos recursos internos. Então, a partir do momento da adesão da Comunidade, sempre que se eleger que um acto comunitário viola a CEDH, o cumprimento do referido artigo abrigará ao esgotamento dos recursos (administrativos e/ou jurisdicionais) do Estado-membro envolvido e da própria Comunidade, que aqui se configurariam, conjuntamente, como recursos "internos". Ao nível nacional, o art. $26^{\circ}$ parece requerer que o recorrente tenha previamente suscitado a questão prévia ao TJCE (art. 177. ${ }^{\circ}$ TCEE). Ao nível comunitário, $o$ art. $26 .^{\circ}$ parece requerer que $o$ recorrente tenha previamente interposto recurso de anulação, ao abrigo do art. $173 .^{\circ}$ TCEE. $O$ efeito conjunto de ambos os artigos do TCEE seria permitir que o TJCE analisasse previamente uma qualquer alegação de violação da $\mathrm{CEDH}$, antes que, eventualmente, a queixa respectiva fosse encaminhada para a Comissão Europeia dos Direitos do Homem.

Contudo, os mecanismos de ambos os artigos podem não garantir essa análise prévia a cargo do TJCE em dois casos: em primeiro lugar, no caso de o órgão jurisdicional nacional de cujas decisões não é susceptível recurso não submeter a questão prévia ao TJCE, contrariando assim o $3 .^{\circ}$ parágrafo do art. $177 .^{\circ}$ TCEE. Neste caso, a Comissão já propôs, para assegurar que o JTCE é sempre interveniente, que seja a própria Comunidade a consultar o TJCE; esta consulta também existiria num segundo caso, o de um Estado não membro da Comunidade recorrer aos órgãos de Estrasburgo com fundamento numa alegada violação da Convenção, pretensamente imputável à Comunidade.

McBRIDE e BROWN ${ }^{35}$ referem que pode haver outro caso em que o TJCE pode não ter ocasião de "defender" a Comunidade; o caso em que um acto de cumprimento de uma obrigação comunitária (seja por via legislativa, regularmente ou simplesmente administrativa) seja impugnado internamente (em qualquer um dos Estados-membros) e, posteriormente, ao esgotamento dos recursos internos, a queixa respectiva seja apresentada à Comissão Europeia. Neste caso, o preenchimento do pressuposto do esgotamento dos recursos "internos" não abrangeria o reenvio prejudicial ao TJCE, pois o acto de cumprimento é um acto da responsabilidade astadual. Então, e exceptuando o caso de esse mesmo acto ser contra o próprio direito comunitário, o conteúdo da obrigação comunitária seria, sem mais, contestado ao nível de Estrasburgo, com prejuízo do princípio da supremacia (e uniformidade de aplicação) do direito comunitário. ${ }^{36}$

No que respeita à questão global (a consulta prévia ao TJCE), BROWN e McBRIDE ${ }^{37}$ consideram a solução proposta pela Comissão como obrigando a 
excessivas demoras processuais, desproporcionadas, tendo em conta que a opinião do TJCE nem sequer produziria efeitos jurídicos no interior da Comunidade e talvez dispensáveis se se considerar a existência de um juiz e de um comissário de "extracção comunitária" nos órgãos da Convenção, como sugerido pela mesma Comissão (v. supra, nota 32).

\section{NOTAS}

1. Este texto foi escrito em princípios de 1990, procedendo-se posteriormente a uma pequena revisão bibliográfica. É de salientar que, em 31 de Outubro desse ano, a Comissão solicitou ao Conselho que a habilitasse a negociar a adesão da Comunidade à Convenção Europeia dos Direitos do Homem, optando-se assim, por conseguinte, por uma das vias de proteç̧ão dos direitos fundamentais referidas neste trabalho. Convira - por último - deixar nota de que existem referências no Tratado da União Europeia tanto à protecção dos direitos fundamentais (n. ${ }^{\circ} 2$ do art. F) como à importância que nesta matéria assume a Convenção Europeia dos Direitos do Homem (n. 1 do art. K.2).

2. Este princípio da não discriminação pode, aliás, ser considerado como uma variante de um princípio geral de não discriminação, constante da Declaração Universal dos Direitos do Homem, mas também da Convenção Europeia dos Direitos do Homem, art. $14 .^{\circ}$, onde se proíbem "distinções (...) fundadas no sexo, raça, cor, língua, religião, opiniões políticas ou outras, origem nacional ou social (...)".

3. Cfr. F. TOMAS (1985: 704).

4. Na expressão de F. TOMAS, ibid..

5. Op. cit., pp. 708 e 709.

6. Mas não exclusivamente: a jurisprudência comunitária assegurou, por exemplo, o direito de defesa (a respeitar não só em processo judicial, mas também em processos administrativos, face às instituições comunitárias), a liberdade de associação e a liberdade sindical.

7. Este caso prendia-se com a situação de um italiano, sindicalista e a viver em França, que tinha sido proibido, pelas autoridades francesas, de residir em determinados departamentos franceses; em causa ficaram o direito ao domicílio, a liberdade de pensamento e de consciência, a liberdade de expressão, a liberdade de associação e de reunião, o direito à livre circulação no interior de um Estado $e$ o direito à livre escolha do local de residência.

8. PESCATORE (1988: 444) considera mesmo que se trata de uma simples aplicação da Convenção ("application ordinaire"), em coerência com a sua posição sobre a (des)necessidade da adesão à $\mathrm{CEDH}$, a referir infra.

9. No Acordão Panasonic, o TJCE julgou da conformidade de regras regulamentares da concorrência com garantias previstas na Convenção. Curiosamente, contemplam-se neste Acordão os "direitos humanos das sociedades comerciais", pois o Tribunal aplica à sociedade Panasonic o art. $8 .^{\circ}$, reconhecendo a inviolabilidade da sua correspondência privada por parte das autoridades públicas, salvo no caso excepcional em que tal seja necessário por razões de segurança ou ordem pública. É interessante notar que o artigo citado anteriormente é um bom exemplo da provável necessidade de se adaptarem algumas normas da Convenção, em caso de adesão; no corpo 
do artigo, nomeadamente no seu n. ${ }^{\circ}$, prevê-se um conjunto de excepções para a sua aplicação, que, nesse caso, teria de ser alargado e/ou adaptado a uma nova realidade, em função dos interesses comunitários. Cfr. BROWN e McBRIDE (1981: 704).

10. Op. cit., pp. 444 ss.

11. WEILER (1986: 1107 e 1124 ss) defende, ao arrepio da maioria dos autores, que esta discussão acerca dos níveis de proteç̧ão tem sido mal orientada; previamente, é preciso definir em função de que interesses é aferido o grau de proteç̧ão de um direito. Isto porque muitas das questões relativas a direitos fundamentais encerram um conflito entre interesses públicos estatais, regionais ou locais, e interesses de particulares. Numa abordagem liberal, dir-se-ia que o nível de protecção mais elevado é aquele que protege em maior medida $o$ indivíduo face ao Estado e à sociedade. Contudo, para certas ordens jurídico-constitucionais, que tendam a dar maior relevo ao interesse social, o melindre da adopção de um determinado padrão, màais do que resultante de uma "ultrapassagem" do seu nível de protecção, pode ser resultante, sobretudo, de uma diferente (mais subjectivista) articulação dos interesses envolvidos.

12. Não se evitaram, de qualquer modo, conflitos entre a Comunidade e as jurisdições constitucionais nacionais, provocadas pelo facto de Constituições de alguns Estados-membros assegurarem um alto nível de garantia dos direitos fundamentais: em 1970 (caso Internationale Handelgesellschaf) o Tribunal Constitucional alemão considerou que o facto de a Comunidade não possuir um catálogo de direitos fundamentais corresponde ao catálogo inserido na Constituição alemã, nem um Parlamento directamente eleito (isto na época), lhe permitia julgar da validade de actos comunitários face à sua Constituição (isto é, face aos seus direitos fundamentais), mesmo que a questão da validade já tivesse sido favoravelmente resolvida pelo TJCE (do ponto de vista da Comunidade, a consequência gravosa desta "rebelião" reside no facto de se estar a pôr em causa o princípio do primado do direito comunitário).

Contudo, esta posição do Tribunal alemão acabaria por dar lugar a uma outra, em 22 de Outubro de 1986 (caso Solange), onde se afirma que, tendo em consideração a evolução da (crescente) protecção dos direitos fundamentais na Comunidade, nomeadamente através da jurisprudência do TJCE, que resultou numa garantia suficiente de respeito pelos mesmos, não mais cabe ao Tribunal Constitucional alemão julgar da validade de direito comunitário derivado face à sua Constituição (ou seja, face aos seus direitos fundamentais). Cfr. CANELAS DE CASTRO (1987: 166-168).

13. Critério defendido por HILF, citado em MARCOUX, op. cit., p. 717.

14. Ver, por todos, DAUSES, op. cit., p. 418.

15. Op. cit., p. 1100

16. Tendo mesmo dado origem ao que WEILER, ironicamente, chamou sea of writing.

17. Na doutrina portuguesa, vejam-se, nomeadamente, MOURA RAMOS (1990) e JALLES (1980).

\section{Por exemplo, LECOURT (1988: 340).}

19. Segundo alguns autores, a adesão seria também um modo de prevenir possíveis conflitos entre a Comunidade e as jurisdições constitucionais nacionais, provocados pelo facto de Constituições de alguns dos Estados-membros assegurarem um alto nível de garantia dos direitos fundamentais. Contra (para além do que já se disse acerca das desvantagens de um comprometimento explícito) pode-se lembrar que a adesão só resolveria (alguns dos) potenciais conflitos entre os Tribunais Constitucionais e o TJCE se o nível de proteç̧ão dos direitos 
fundamentais garantido pela Convenção pelo menos igualasse aquele garantido pelo conjunto das jurisdições nacionais. Tal parece não acontecer.

20. A CEDH protege em primeiro lugar os direitos civis e políticos, como o dirieto à vida (art..$^{\circ}$ ), a proibição da tortura (art. $3 .^{\circ}$ ), da escravidão ou servidão (art. $4 .^{\circ}$ ), nunca reforçando, ou mesmo sendo deficitária, em relação a direitos económicos e sociais, que importam especialmente no âmbito comunitário. Todavia, este desfasamento tem alguma tendência a diminuir, à medida que sucessivos protocolos adicionais foram introduzindo disposições relativas a direitos económicos e sociais; existe desde já convergência de objectivos em áreas como sejam a liberdade de expressão, a proibição de discriminação (arts. $14 .^{\circ} \mathrm{CEDH}$ e $7 .^{\circ}$ e $119 .^{\circ} \mathrm{TCEE}$ ), a protecção da propriedade, $\mathrm{o}$ direito a exercer uma profissão, o direito à justiça, o direito à privacidade e a liberdade de associação.

21. Op. cit., p. 563.

22. Todavia, colocam-se alguns problemas preliminares: por exemplo, é necessário definir qual o procedimento a adopatar pela Comunidade para aderir à CEDH? A via mais simples, defendida pela doutrina (F. TOMAS, op. cit., p.715) e pela Comissão, assenta na aplicação do art. $235 .^{\circ}$ do TCEE, que não implica a participação dos Estados-membros, o que acelera o processo (ao contrário do art. $236 .^{\circ}$, o indicado se se optar pela elaboração de um catálogo). Tal aplicação fundamenta-se pelo facto de a proteç̧ão dos direitos fundamentais se ter transformado, no âmbito comunitário, num "dos objectivos da Comunidade" (no sentido do art. 235..$^{\circ}$, vista a jurisprudência comunitária e a co-responsabilização por essa jurisprudência por parte das outras instituições. Se assim É, então a adesão será o meio, não previsto originariamente, de prosseguir esse objectivo.

23. Op. cit., p. 453.

24. Sobre a questão da pretensa transferência de poderes soberanos dos Estados-membros para a Comunidade veja-se FAUSTO DE QUADROS (1991: $196 \mathrm{ss}$ ).

25. Para PESCATORE apenas será necessário que o Conselho $\left(1 .^{\circ}\right)$ reconheça o direito de recurso individual e $\left(2 .^{\circ}\right)$ reconheça a obrigatoriedade da jurisdição do TEDH.

26. Op. cit., p. 708.

27. Nem poderia ter ocorrido, pois, pelo art. $66^{\circ}$ da CEDH, para se aderir é necessário ser-se previamente membro do Conselho da Europa. Ora, pelos Estatutos do Conselho da Europa (arts. $4 .^{\circ}$ e $5{ }^{\circ}$ ), só podem aderir a este Conselho estados e países.

28. Op. cit., p. 421.

29. Op. cit., p. 705.

30. Quanto a consequências processuais, PESCATORE, de acordo com a sua posição, salienta que essas consequências têm que ser interpretadas não como resultantes de um "acordo" entre a Comunidade e os orgãos da Convenção, mas como resultantes do estado de "sujeição" da Comunidade à Convenção.

31. La Coopération européenne dans le domaine des droits de l'homme, Colloque de Nancy de la S.F.P. Dr. I., L'Éurope dans les relations internationales, Ed. Pedone, Paris, 1982, p. 174, apud F. TOMAS, op. cit., p. 716.

32. Neste caso, contaríamos com a produção de efeitos no funcionamento dos seus 6́rgãos: a Comunidade teria que participar nos órgãos da CEDH (Comité de Ministros, Comissão e Tri- 
bunal). O Memorandum da Comissão propõe que um novo juiz e um novo comissário passem a fazer parte dos órgãos respectivos, embora a título individual. Isto para, por um lado, respeitar (através de uma analogia) as regras de funcionamento desses órgãos e para, por outro, facilitar o contacto do TEDH como o ordenamento jurídico comunitário.

33. Op. cit., p. 338.

34. MENDELSHON (1983: 125) pretende refutar a tese da autonomia da jurisdição da CEDH, baseando-se na aplicação do art. 27/1/b da CEDH. Para este autor, quando um caso levanta questões de direito comunitário e contende com a $\mathrm{CEDH}$, ambas as jurisdições têm competência. Sendo assim, se, em primeiro lugar, é proposta uma acção no TJCE, esta propositura pode ser considerada como "uma submissão" a outra "instância internacional de inquérito ou de decisão", impossibilitando a admissibilidade posterior da mesma "reclamação" na Comissão Europeia. No entanto, o autor reconhece que essa norma não foi elaborada pensando no TJCE, que ainda não existia, mas sim em organismos internacionais de funcionamento similar ao da CEDH. Contra também se pode argumentar com o carácter finalístico da jurisdição comunitária.

35. Op. cit., p. 197.

36. BROWN e McBRIDE (op. cit., p. 703) referem ainda que, ao abrigo do $2 .^{\circ}$ parágrafo do art. $177 .^{\circ}$, o órgão jurisdicional do Estado - membro pode considerar desnecessário requerer a apreciação, por parte do TJCE, de uma eventual questão prévia e acescentam que também nessa situação o TJCE fica impossibilitado de analisar antecipadamente essa questão. Portanto justificar-se-ia igualmente neste caso a alteração processual sugerida pela Comissão. Tal ressalva não merece a nossa concordância, pois, confrontando os parágrafos $2 .^{\circ}$ e $3 .^{\circ}$ do referido artigo, conclui-se o contrário, que o órgão jurisdicional referido no $2{ }^{\circ}$ é um órgão de cujas decisões se pode recorrer. Se tal acontece, então o pressuposto do esgotamento dos recursos internos não é cumprido e fica assim prejudicada a admissibilidade da queixa apresentada à Comissão Europeia; por conseguinte, perde razão de ser a consulta prévia ao TJCE.

37. Op. cit., p. 704.

\section{BIBLIOGRAFIA}

AKEHURST, Michael, 1981, "The application of general principles of law by the Court of Justice of the European Communities", The British Year Book of International Law, Oxford, pp. 29 ss.

BARBOSA DE MELO, António, 1986, Notas de contencioso comunitário, Coimbra (sumários das aulas da disciplina de Contencioso Comunitário, do Curso de Estudos Europeus, Faculdade de Direito de Coimbra).

BROWN, L. Neville \& McBRIDE, Jeremy, 1981, "Observations on the proposed accession by the European Community to the European Convention of Human Rights", The American Journal of Comparative Law, California, 29.

CAMPOS, João Mota de, 1988, Direito Comunitário, $2 .^{\circ}$ vol., (o ordenamento jurídico comunitário), 2." ed., Lisboa, Fundação Calouste Gulbenkian. 
CANELAS DE CASTRO, Paulo Jorge, 1987, Rapports entre droit interne et droit international; la problématique dans la Constitution Portugaise de 1976, Nice, Universidade de Nice / Institut du Droit de la Paix et du Développement.

COMISSÃO DA COMUNIDADE, 1979, “Memorandum sobre a adesão das Comunidades à Convenção Europeia dos Direitos do Homem", Boletim das Comunidades Europeias (versões em inglês ou em francês), suplemento $n .^{\circ} 2$.

CONSELHO DA EUROPA, s/ data, A Protecção dos Direitos do Homem na Europa, Conselho da Europa.

DAUSES, Manfred A., 1984, 'La protection des Droits Fondamentaux dans l'ordre juridique communautaire", Revue Trimestrelle de Droit Européen, Paris, Ano 20, n. 3.

FAUSTO, de Quadros, 1991, Direito das Comunidades Europeias e Direito Internacional Público: contributo para o estudo da natureza jurídica do Direito comunitário Europeu, Coimbra, Livraria Almedina.

FERNANDEZ TOMAS, António F., 1985, 'La adhesion de les Comunidades Europeas al Convenio Europeo para la Protección de los Derechos Humanos (CEDH): um intento de solución al problema de la protección de los Derechos Fundamentales en el ambito comunitário", Revista de Instituciones Europeas, $12, \mathrm{n} .{ }^{\circ} 3$.

JALLES, Isabel, 1980, “Os Direitos da Pessoa na Comunidade Europeia", Documentação $e$ Direito Comparado, $\mathrm{n}^{\circ} 2$, pp. 27 ss.

LECOURT, Robert, 1988, "Cour Européene des Droits de l'Homme et Cour de Justice des Communautés Européennes", in Matscher, Franz e Herbert Petzold, orgs., Protection des droits de l'homme: la dimension européenne (mélanges en l'honneur de Gerard J. Wiarda), Carl Heymanns Verlag KG.

LOUIS, Jean-Victor, 1986, "Le concept de Droits Fondamentaux dans le droit de la Communauté Économique Européenne", Revue internationale de droit comparé, ano $35 .^{\circ}, \mathrm{n} .^{\circ} 1$, Janeiro-Março.

McBRIDE, Jeremy, \& L. Neville, 1982, "The United Kingdom, The European Community and the European Convention of Human Rights", Yearbook of European Law, Oxford, 1981, I, pp. 167 ss.

MENDELSON, M. H., 1983, "The impact of European Community Law on the Implementation of the European Convention of Human Rights", Yearbook of European Law, 3.

MOURA RAMOS, Rui Manuel, 1990, L'adhésion de la Communauté à la Convention Européenne des droits de l'homme, Coimbra.

PESCATORE, Pierre, 1981, "The context and significance of Fundamental Rights in the law of the European Communities", Human Rights Law Journal, Estrasburgo, 2, partes 3-4, Dezembro.

PESCATORE, Pierre, 1988, "La Cour de Justice des Communautés Européennes et la Convention Européenne des Droits de l'Homme”, in Matscher, Franz e Herbert Petzold, orgs., Protection des droits de l'homme: la dimension européenne (mélanges en l'honneur de Gérard J. Wiarda), Carl Heymanns Verlag KG.

WEILER, Joseph H. H., 1986, "Eurocracy and Distrust: some questions concerning the role of the European Court of Justice in the protection of Fundamental Human Rights within the legal order of the European Communities", Washington Law Review, 61, número 3, Julho. 